\title{
Bi-directional TRIAC fault-protection technique for Z-source half-bridge converter-fed AC motor Drives
}

\author{
Vivek Sharma, Student Member, IEEE, M. J. Hossain, Senior Member, IEEE, \\ S. M. Nawazish Ali, Student Member, IEEE and Muhammad Kashif, Student Member, IEEE \\ School of Engineering, Macquarie University, Sydney, NSW 2109, Australia \\ Email: vivek.sharma2@hdr.mq.edu.au
}

\begin{abstract}
With higher demand for power electronic converters in single-phase drive systems, the concern for fault-tolerant schemes has risen in the past decade. Also, the demand for Impedance $(Z)$-source converters, facilitating single-stage power conversion with high voltage gain, has increased for induction motor drive systems. This paper presents an efficient two TRIAC fault-protection technique for the impedance-source half-bridge converter-fed induction motor drive system. The study is analyzed thorougly under pre-fault and post-fault conditions and a comparative analysis is presented in this paper. Simulation circuits with relevant harmonic spectra are assessed. From the detailed analysis, it is found that the occurrence of faults increases harmonic distortion to a high level, making the drive system ineligible for operation. The proposed fault-protection technique proves to be an efficient topology in maintaining continuous power flow during faults.
\end{abstract}

Index Terms-fault, converter, drive system, total harmonic distortion, induction motor

\section{INTRODUCTION}

The selection of adjustable speed ac motor drives is largely dependent on the reliability of the drive. The efficiency, modes of operation and rated output of the ac drives are required to be studied before implementation. Power-electronic supply topologies are configured based on the number of phases required to install the induction-motor drives. Single-phase induction motors are widely used in domestic applications where three-phase supply is not readily available. The advantages of capacitor-run single-phase induction motor is highlighted in [1], which suggests that a capacitor-run single-phase motor is recommended on the basis of simplicity, reliability, and cost-effectiveness for single-phase drive systems. The low power motor applications uses batteries as a constant source of power irrespective of the presence of a grid/generating source. Cost-effective operation requires the battery-voltage magnitude to be boosted to a significantly high magnitude to facilitate motor operation. The single-stage conversion capability of the impedance-source inverter proves it to be a better topology for boost operation. The comparative analysis of conventional inverter-fed drives with z-source inverter-fed drives is presented in [2]. Also, a harmonic spectral study of Z-source inverter drives is presented in [3], suggesting that the Z-source topology stands out from conventional techniques for dc-dc power conversion. Single-phase induction motor drives require half-bridge converters for the switching operations of the inverter module. Conventional half-bridge converters are susceptible to short circuits and low output-voltage gain. The study presented by [4] shows a model of highly efficient zsource half-bridge converter. This model solves the problem of shoot-through and limited voltage gain and provides a broader range of output voltage. Impedance-source half-bridge converter is highly recommended for applications with a limited dc supply to overcome the requirement for an additional dcdc converter, which increases the cost. Single-phase drive systems are sensitive to faults which affect the operating hours of the drive system. The safety-critical standards AS 61800.32005 of the Australian government deals with the operation of adjustable-speed electric-power drive systems. It depicts the nominal standards of operation for a drive during fault occurrence. Hence, the need for a protection technique for the operating system becomes a matter of concern for applications requiring constant operation.

Fault tolerant techniques for electric drives are getting popular in current industries. A comparative analysis of various fault-tolerant topologies for three phase $\mathrm{AC}$ drives is presented in [5], although the literature lacks consideration for single-phase ac drives which are more popular than threephase drives. The study [6] presents a three-level voltage source boost-inverter with quasi Z-source technology to give a rated balanced $\mathrm{AC}$ voltage in open-circuit fault condition. However, the study lacks harmonic analysis over the complete system. A fast method for fault detection is proposed in [7] for quasi Z-source topology but lacks the effects of load harmonics over the complete system. Additionally, the faulttolerant technique given by [8] is the most efficient technique of all proposed fault-tolerant techniques. However, this study lacks the analysis of single-phase ac drives. Hence, this paper extends the usage of a proposed fault-tolerant technique for single-phase ac drives.

Based on the above literature review, it is inferred that previous studies lack a study of fault-tolerant techniques, especially for single-phase ac drives in terms of the harmonic spectrum under fault conditions. The previous work of author [9] has implemented a fault-protection technique for Z-source full bridge inverter fed drive. In recent years, Z-source halfbridge converters have gain popularity over Z-source full bridge converter for single-phase induction motor drives. This paper deals with a simulation study of Z-source half-bridge converter-fed single-phase ac drives. Furthermore, a faultprotection technique is discussed for the developed model to 
deal with common faults occurring in the system. This paper proposes use of Z-source half-bridge converter for singlephase ac drives as an efficient method to obtain a boosted output voltage. The efficacy of the proposed method is presented by the desired harmonic-simulation results with and without proposed fault protection circuit. The study emphasized on no compromise between the performance and cost of the inverter module. This paper is organized as follows. In Section II, the design and control specification of the proposed system is discussed. In Section III, simulation results are presented for the considered faults. Section IV explains the fault-protection technique used in the paper. In section V, the obtained results are tabulated and analyzed. In Section VI, a conclusion of this paper is given with future scope.

\section{System Design AND Modeling}

\section{A. Z-source half-bridge converter-fed Induction-Motor drive}

The magnitude of the high current flowing through the legs of conventional half-bridge converters during the shootthrough state causes the circuit break down. This problem is overcome by the Z-source half-bridge topology which uses inductors to limit the high current during shoot-through state. The Z-source half-bridge converter consists of capacitors $C_{1}$ and $C_{2}$ and inductors $L_{1}$ and $L_{2}$ combined with a traditional converter having capacitors $C_{d 1}$ and $C_{d 2}$. To facilitate a unidirectional flow of power, diodes $D_{1}$ and $D_{2}$ are placed in the circuitry [4]. This topology is fed to a single-phase inductionmotor drive consisting of capacitor-start-run induction motor as shown in Fig. 1. The choice of this specific type of motor is based on voltage utility factor of the inverter module and the performance characteristics of the motor. The torque-speed characteristics of this motor are suitable for the proposed modulation technique used to drive the inverter module for the shoot-through and non-shoot through states.

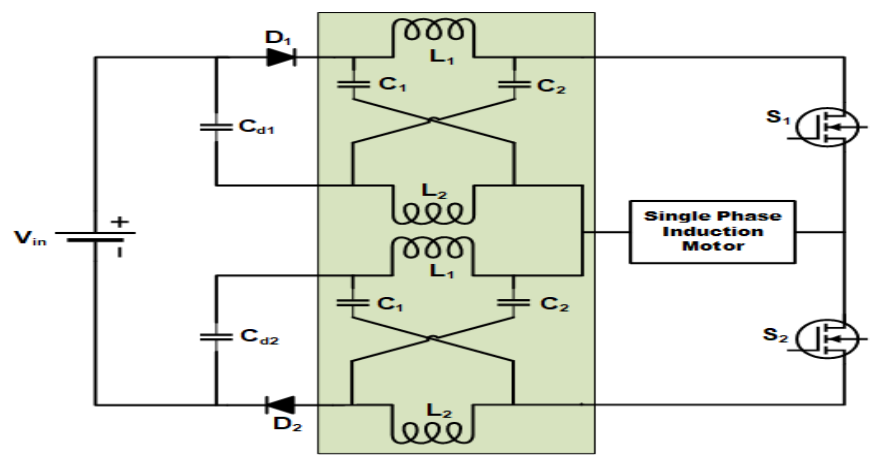

Fig. 1. Circuit diagram of Z-source half-bridge converter-fed IM drive

The voltage stress on the power-electronic switches is reduced by an using improved modulation technique. The authors in [10] proposed a high voltage-gain pulse-width modulation to overcome demerits of conventional modulation schemes, which are dependent on the duty ratio and modulation index. The presented modulation scheme is modified and implemented for the inverter module of the single-phase ac drive presented in the paper. The basic reference voltages are given as:

$$
\begin{aligned}
& V_{+}=M \sin (\omega t) \\
& V_{-}=M \cos (\omega t)
\end{aligned}
$$

where $\mathrm{M}$ is the modulation index.

The modulating signals of the inverter module are obtained by comparing the sinusoidal values with a triangular carrier waveform. The frequency of the carrier waveform is kept less than that of sinusoidal signals, which results in a high voltage gain corresponding to the conventional SPWM. The proposed modulation scheme considered in this paper is shown in Fig. 2.

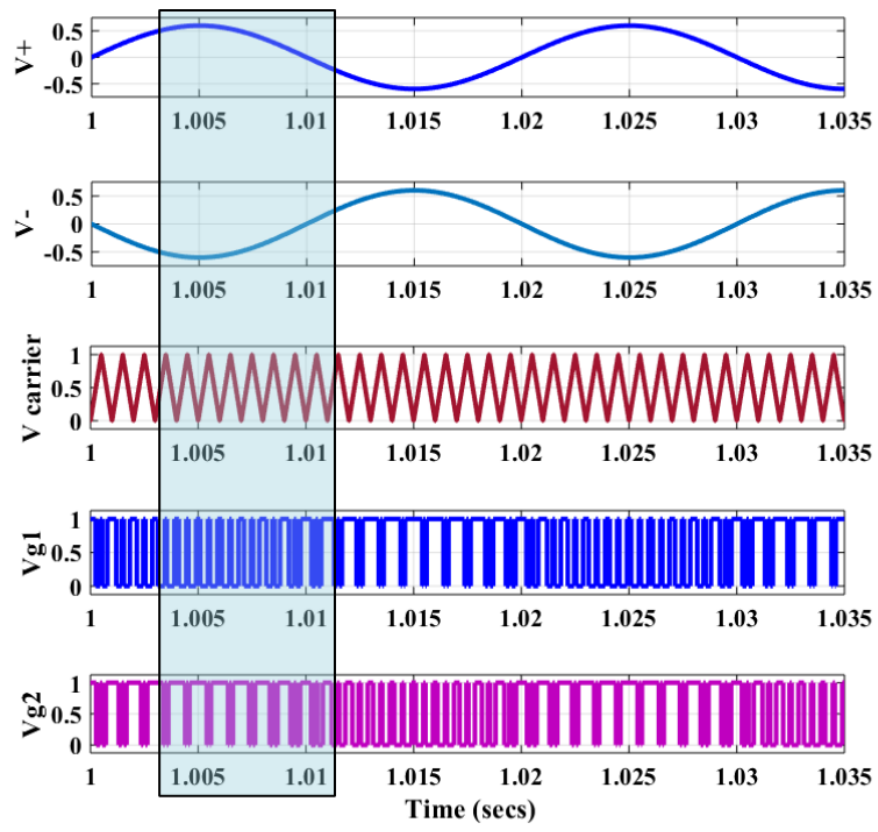

Fig. 2. Modulation scheme for the converter module

The modulation technique is chosen in such a way that all the shoot-through states are added to the null intervals by keeping operating interval constant. The modulation scheme used in the inverter module also reduces ripple in the capacitor voltage as well as the inductor current under normal operating conditions. This is because of the low-sensitivity parameter of the implemented modulation technique. During operation, the dead time of the driving pulses is ignored and the effects of freewheeling diodes are not considered so as to compensate for the linear load characteristics.

\section{B. Design of Inductors and Capacitors}

The boost control used in this paper is characterized by the inductors and capacitors connected in the Z-source network. Two Z-source networks are connected in the circuit diagram to avoid any imbalance in the input capacitor voltage injected by the mid-point capacitances connected across the input. The 
calculations for the parameters of the Z-network are given in this part.

The inductor of the network is chosen such that the ripple of the inductor current has negligible effect on the stability of the network. The inductor can be calculated as:

$$
L=\frac{V_{L 2} d t_{L}}{d i_{L 2}}
$$

The design of capacitor is dependent on the magnitude of the capacitive current under the permitted fluctuations of value for the given switching period. The capacitor can be calculated as:

$$
C=\frac{i_{C 2} d t}{d V_{C 2}}
$$

The calculated parameters of the Z-network are given in Table I.

TABLE I

PARAMETERS OF Z-NETWORK

\begin{tabular}{|c|c|}
\hline Parameter & Value \\
\hline Inductor, $L_{1}=L_{2}$ & $1 \mathrm{mH}$ \\
\hline Capacitor, $C_{1}=C_{2}$ & $1000 \mu \mathrm{F}$ \\
\hline
\end{tabular}

\section{ANALYSiS OF SyStem RELiability}

In this section, simulation results of the proposed circuitry are presented for pre-fault and post-fault conditions to show the adverse effects of faults on the electric drive system. The occurrence of faults degrades the motor characteristics and distorts the current waveform as described in this part. The parameters used in the simulation study of the Z-source half-bridge converter-fed single-phase induction-motor drive are as follows: $V_{i n}=48 \mathrm{~V}$, switching frequency $=10 \mathrm{kHz}$, $V_{\text {out }}=96 \mathrm{~V}$. The Z-network provides a boost factor, $\mathrm{B}=2$. The parameters of induction motor are given in Table II. The reliability of the proposed drive system is analyzed under the following conditions:

(i) without fault

(ii) gate-drive fault

(iii) blown-off MOSFET fault

\section{A. Case I: Without Fault}

The main objective of this case study is to investigate the performance of the proposed drive system under normal operation conditions. The input and output voltage waveforms for the proposed circuit are given in Fig. 3.

The efficacy of the proposed protection technique is determined by the level of Total harmonic distortion. The total harmonic distortion is defined as measurement of harmonic distortions in an signal. The expression for total harmonic distortion is given in 5 .

$$
T H D=\frac{\sqrt{V_{2}^{2}+V_{3}^{2}+\ldots}}{V_{1}}
$$

TABLE II

MOTOR PARAMETERS

\begin{tabular}{|c|c|}
\hline Parameter & Value \\
\hline Nominal Power & $250 \mathrm{~W}$ \\
\hline Nominal Voltage & $110 \mathrm{~V}$ \\
\hline Nominal frequency & $50 \mathrm{~Hz}$ \\
\hline Number of poles & 4 \\
\hline
\end{tabular}
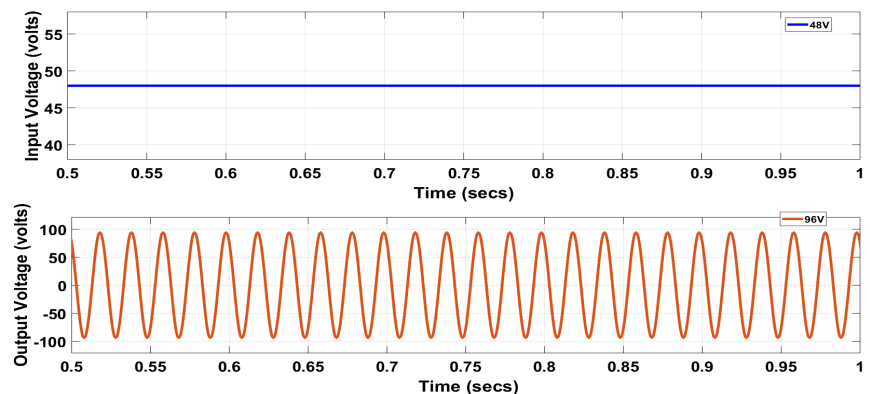

Fig. 3. Input and output voltage waveforms of Z-source half-bridge converterfed IM drive

where $V_{n}$ is RMS voltage of the nth harmonic and $\mathrm{n}=1$ is the fundamental frequency. The harmonic spectrum of the obtained output voltage waveform is shown in Fig. 4. The spectrum shows $0.42 \%$ of harmonic distortion in the output waveform with a high-magnitude fundamental component. The obtained sinusoidal waveform is fed to the single-phase induction motor. Single-phase induction motors consist of a laminated core with two windings, namely main winding and auxiliary winding. The chosen capacitor-start-run induction motor has the lowest harmonic distortion sensitivity [11].

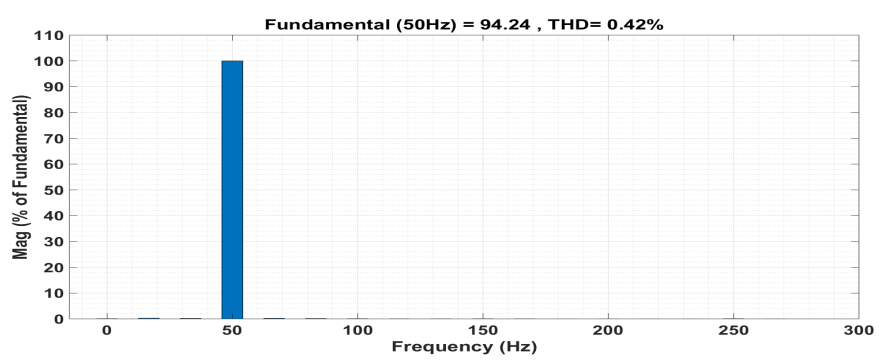

Fig. 4. Harmonic Spectrum of proposed induction motor drive without fault

The simulation waveform of the motor characteristics are given in Fig. 5. The magnitude of the electromagnetic torque obtained has higher value for the proposed Z-source halfbridge converter-fed drive than the conventional half-bridge converters. The speed curve shows that the speed increases gradually to the rated speed. The proposed induction-motor drive has lower torque pulsations and hence contributes to a reliable drive system. 

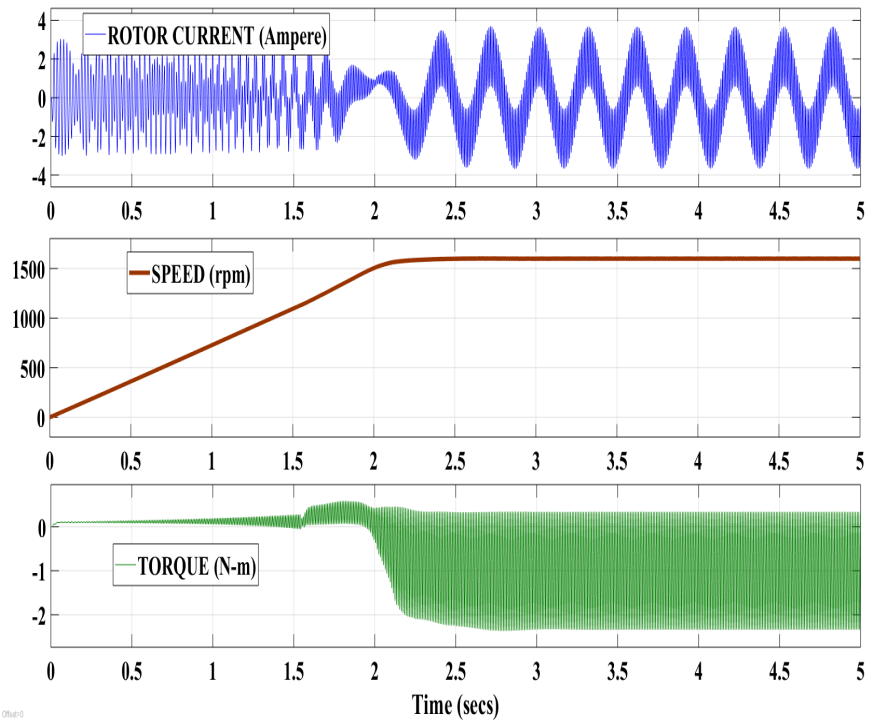

Fig. 5. Torque-speed characteristics of motor under normal operation

\section{B. Case II:With Fault}

The modern industrial drive consists of a power electronic converter-fed to a electric motor. The frequent switching of power-electronic switches can lead to severe fault conditions. Most of the faults affect the drive system and the machine will stop running. The common faults that can occur in the system are open-circuit and short-circuit faults. This paper considers the harmonic spectrum during each fault. The simulation circuits and output-current waveforms are presented in this part.

1) Fault at MOSFET gate terminal: The main cause of a gate-drive fault is thermal stress on the switch due to switching at high frequency. These faults affect the system performance and cause current distortions in the output waveform. These distortions are characterized by noise and vibrations at the load side. These faults are a real threat to operations involving high-speed motor applications. In MATLAB/Simulink, this fault condition is achieved by opening the gate terminal of a MOSFET in the phase leg. The simulation circuit diagram of the proposed induction-motor drive system with a gate-drive fault is given in Fig. 6.

The output current waveform during the gate-drive fault is given in Fig. 7. The output current waveform is totally distorted and the motor current gradually decreases to zero. This leads to a shut down of the drive system. The harmonic spectrum of the proposed system during this fault condition is given in Fig. 8. The harmonic spectrum in Fig. 6 shows a large dip in the magnitude of the fundamental component of frequency.

The total harmonic distortion increases to $107.95 \%$. The higher-order harmonics are dominant, degrading the power quality of the system. The distortions due to this fault make the air gap flux, between the stator and rotor, non-sinusoidal, which creates unwanted torque. This condition is not suitable

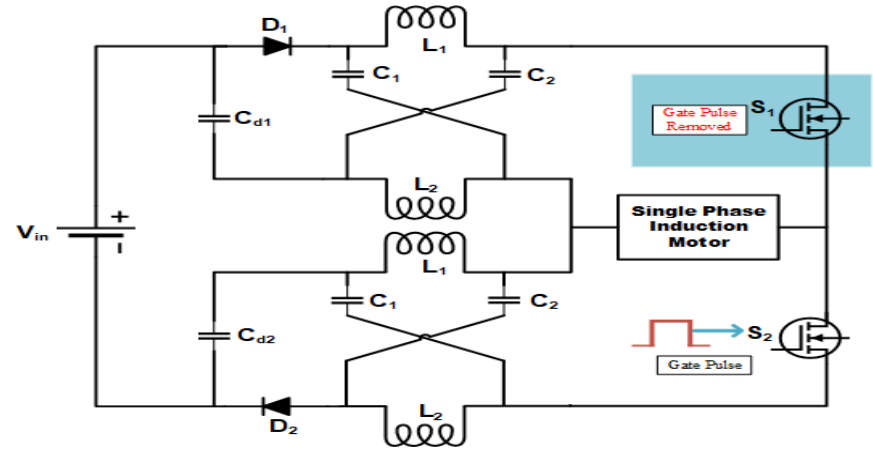

Fig. 6. Simulation diagram of Z-source half bridge converter-fed IM drive with gate-drive fault

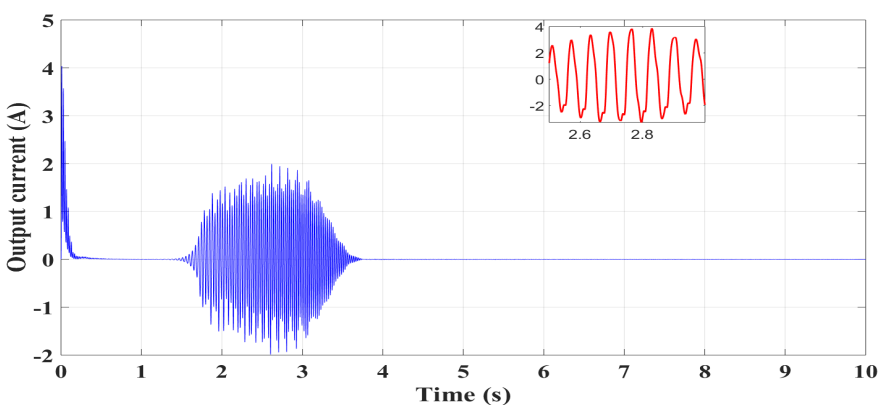

Fig. 7. Output current waveform with the gate-drive fault

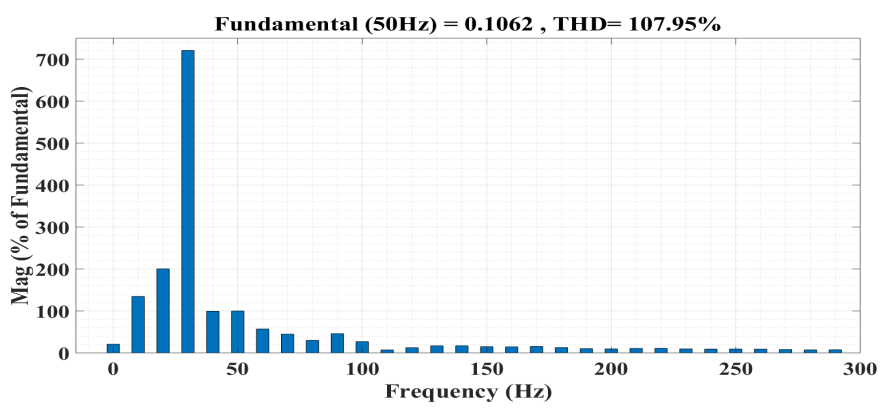

Fig. 8. Harmonic spectrum of the proposed circuit with gate-drive fault

for drive operation.

2) Blown-off MOSFET Fault: Semiconductor switching failures or soldering failures cause thermal stress in power devices leading to the blown-off condition. Temperature overshoot is the major cause of device failure for applications requiring constant operation. In this part of study, the proposed system is simulated for a MOSFET blown-off fault. This condition is achieved by replacing the MOSFET by a high resistance of the order of $1 \mathrm{Megohm}$. This condition resembles open circuiting of the semiconductor switch. The simulation circuit of the proposed system for a MOSFET blown-off fault is given in Fig. 9.

The output current waveform for a MOSFET blown-off fault is shown in Fig. 10. The output current waveform shows a sudden spike in magnitude which is dangerous for the safe operation of motor drives. The current obtained is above the 
short-circuit current limit of the proposed system. This leads to higher heating losses and permanent damage to the motor drive. The whole system needs to be shut down on occurrence of this fault, affecting the reliability of the proposed topology.

The harmonic spectrum of the proposed system under a MOSFET blown-off fault is presented in Fig. 11. The harmonic spectrum shows a high level of distortion occurring due to the blown-off fault. The total harmonic distortion increases to a value of $61.67 \%$. This is due to the high current injection into the system during the fault. The torquespeed characteristics of induction motor is shown in Fig. 12. With introduction of fault, the harmonic component induces breaking action leading to dip in torque value with increase in speed. The torque further reduces to zero as speed approaches to value above synchronous speed. The rotor current drastically reduces to zero in event of fault.

\section{FAult-Protection TeChNique}

The above fault analysis shows that the occurrence of faults degrades the performance and reliability of the proposed system significantly. The effect of faults becomes more considerable in interlinked topologies. If a fault occurs at one drive, the whole system has to be shut down in order to prevent damage to the machines. This leads to the need for an efficient fault-protection technique. This paper presents a fault-protection technique for the above-considered system of the induction-motor drive. The simulation circuit diagram of the proposed fault-protection technique is shown in Fig. 13.

The circuit diagram is reconfigured to compensate for device failure during a fault occurrence. The above analysis shows that the effects of faults can be minimized by providing an extra leg for current flow during the fault. This is achieved in the proposed fault-protection technique by putting two TRIACs in an anti-parallel configuration. These TRIACs between the input and motor terminals will allow the circuit to continue operation of the inverter-fed drive even with the faults analyzed in Section III. The harmonic spectrum of the proposed circuit under a gate-drive fault with the proposed fault-protection strategy is shown in Fig. 14.

Similarly, the harmonic spectrum of the proposed circuit under a blown-off fault with the proposed fault-protection

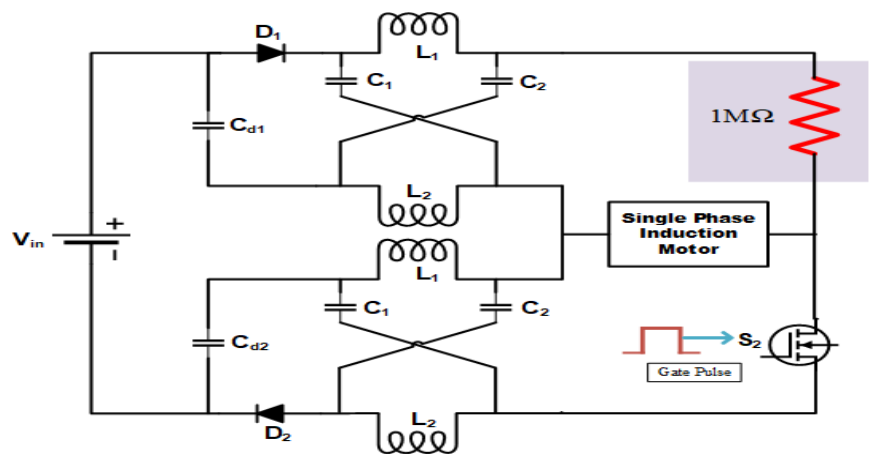

Fig. 9. Simulation diagram of Z-source half bridge converter-fed IM drive with MOSFET blown-off fault

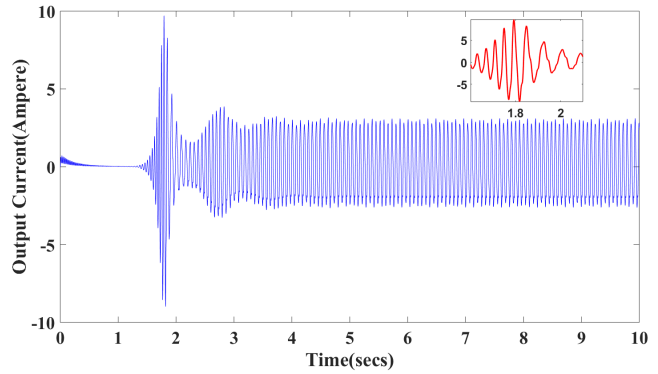

Fig. 10. Output current waveform with MOSFET blown-off fault

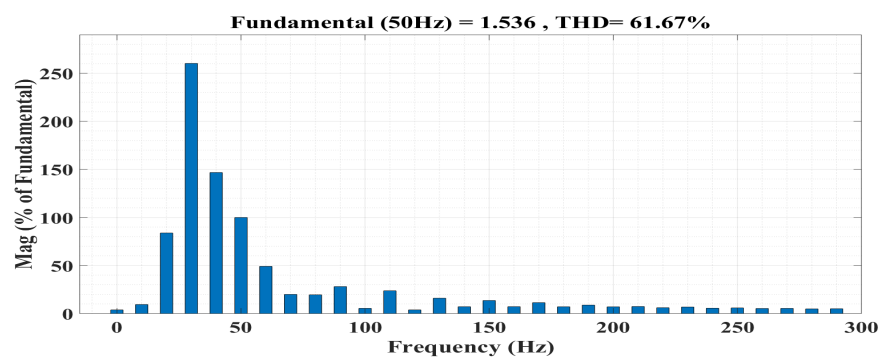

Fig. 11. Harmonic spectrum of the proposed drive with MOSFET blown-off fault
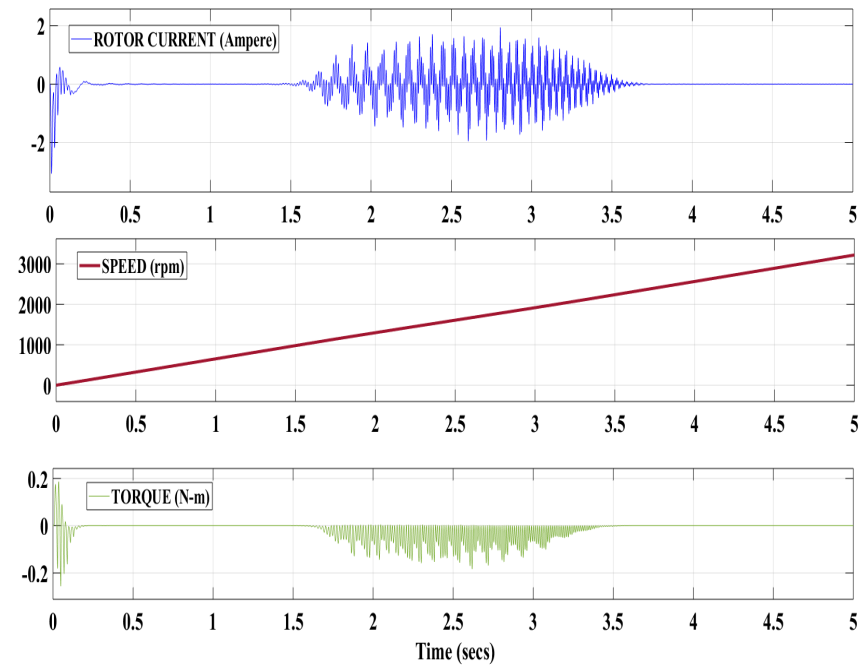

Fig. 12. Torque-speed characteristics of motor under faulty condition

strategy is shown in Fig. 15. The harmonic spectral study from Fig. 14 and Fig. 15 shows the merits of the proposed faultprotection strategy under faults. The distortions imparted by the faults are reduced significantly.

\section{REsults}

The main aim of this section is to compare the performance of the proposed drive system with and without using the designed protection circuit. From the above simulations, it is observed that the fault-protection strategy used in this paper is highly efficient for a blown-off fault as compared to a gate-drive fault. Though this technique reduces the harmonics 


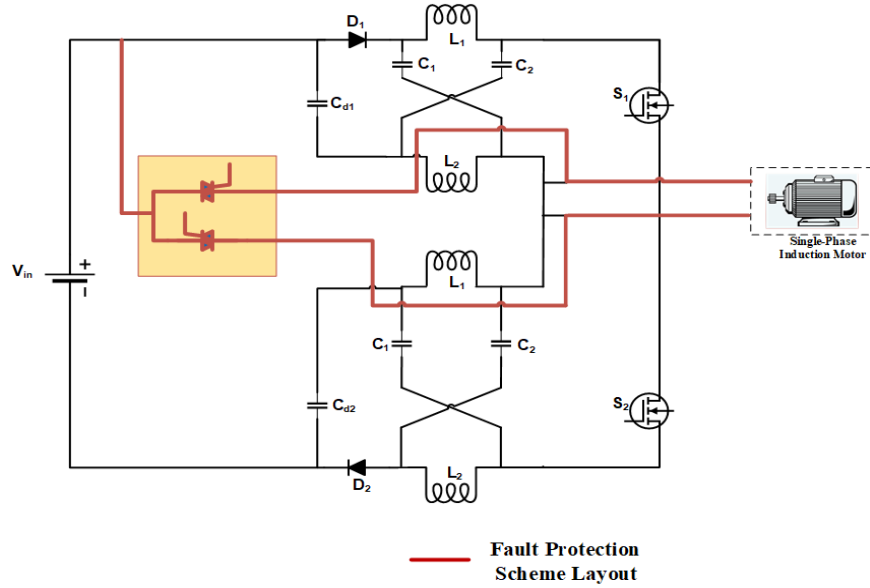

Fig. 13. Simulation circuit of proposed fault-protection technique

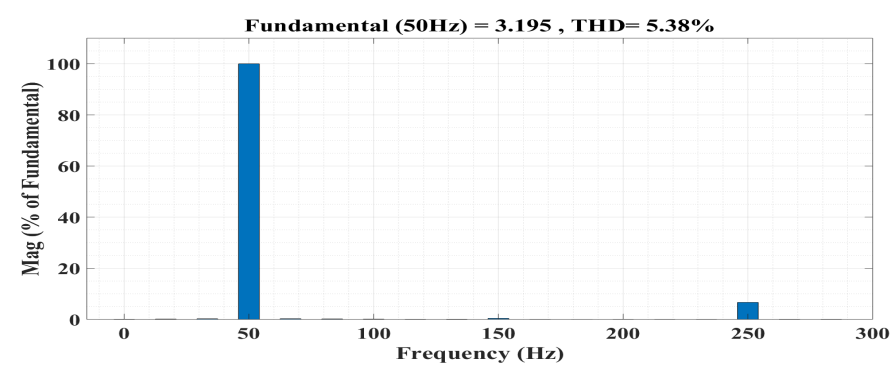

Fig. 14. Harmonic spectrum under gate-drive fault with fault-protection technique

occurring due to the faults, the magnitude of the fundamental component is less with the gate-drive fault. This problem can be overcome by using a high-pass filter. The results are shown in table III.

The results shows that the total harmonic distortion decreases from a high magnitude of $107.95 \%$ to $5.38 \%$ for a gatedrive fault by using the proposed fault-protection technique. Also, the harmonic distortion reduces to a low magnitude of $7.24 \%$ from $61.67 \%$ for a MOSFET blown-off fault.

\section{Conclusion And Future Scope}

This paper presents a comprehensive analysis of the effects of gate-drive and blown-off faults on the Z-source half-bridge converter-fed single-phase induction motor drive.

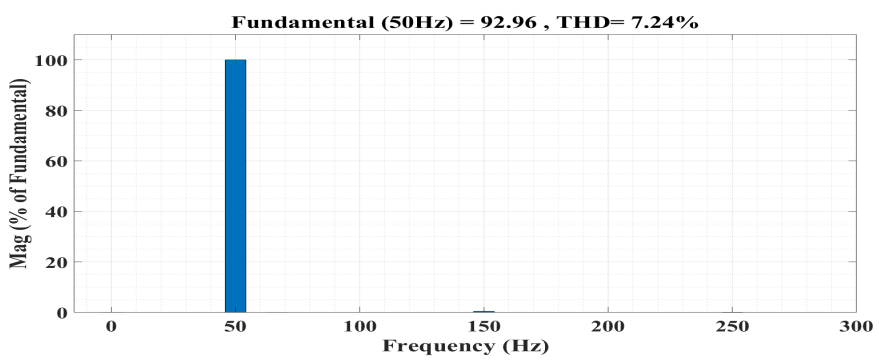

Fig. 15. Harmonic spectrum under blown-off fault with fault-protection technique
TABLE III

HARMONIC SPECTRAL ANALYSIS

\begin{tabular}{|c|c|c|}
\hline Nature of Fault & $\begin{array}{c}\text { \% of THD } \\
\text { Without } \\
\text { Protection } \\
\text { circuit }\end{array}$ & $\begin{array}{c}\text { \% of THD } \\
\text { With } \\
\text { Protection } \\
\text { circuit }\end{array}$ \\
\hline (i) Without fault & 0.42 & - \\
\hline (ii) Gate-drive fault & 107.95 & 5.38 \\
\hline (iii) MOSFET blown-off fault & 61.67 & 7.24 \\
\hline
\end{tabular}

Further, an efficient fault protection technique is presented in this paper with relevant harmonic spectra obtained through MATLAB/Simulink. From this study, it is concluded that the proposed fault-protection circuit is efficient for single-phase ac drives for suppressing harmonic distortion in the output waveform.

The future aim of this research is to implement the proposed drive system in the laboratory and validate the simulation results with a laboratory setup. With the growing demand for renewable energy sources, the proposed motor drive system can be implemented with an inverter module fed from a PV array. To extend its application, the module can be developed for three-phase drive systems.

\section{REFERENCES}

[1] C. Mademlis, I. Kioskeridis, and T. Theodoulidis, "Optimization of single-phase induction motors-part i: maximum energy efficiency control," IEEE Transactions on Energy Conversion, vol. 20, no. 1, pp. 187195, March 2005.

[2] V. Sharma, P. Saini, S. Garg, and B. Negi, "Comparative analysis of vsi, csi and zsi fed induction motor drive system," in 2016 3rd International Conference on Computing for Sustainable Global Development (INDIACom), March 2016, pp. 1188-1191.

[3] V. Sharma, N. Rawat, and P. Garg, "Fault diagnosis of single phase zsource inverter," in 2015 Second International Conference on Advances in Computing and Communication Engineering, May 2015, pp. 108111.

[4] G. Zhang, Z. Li, B. Zhang, D. Qiu, W. Xiao, and W. A. Halang, "A z-source half-bridge converter," IEEE Transactions on Industrial Electronics, vol. 61, no. 3, pp. 1269-1279, March 2014.

[5] B. A. Welchko, T. A. Lipo, T. M. Jahns, and S. E. Schulz, "Fault tolerant three-phase ac motor drive topologies: a comparison of features, cost, and limitations," IEEE Transactions on Power Electronics, vol. 19, no. 4, pp. 1108-1116, July 2004.

[6] M. Sahoo and S. Keerthipati, "Fault tolerant three-level boost inverter with reduced source and lc count," IET Power Electronics, vol. 11, no. 2 , pp. 399-405, 2018.

[7] M. Yaghoubi, J. S. Moghani, N. Noroozi, and M. R. Zolghadri, "Igbt open-circuit fault diagnosis in a quasi-z-source inverter," IEEE Transactions on Industrial Electronics, pp. 1-1, 2018.

[8] V. F. Pires, D. Foito, and A. Cordeiro, "Three-phase qz-source inverter with fault tolerant capability," IET Power Electronics, vol. 10, no. 14, pp. 1852-1858, 2017.

[9] V. Sharma, M. J. Hossain, and S. M. N. Ali, "Fault protection technique for zsi-fed single-phase induction-motor drive system," in 2018 IEEE Region Ten Symposium (TENSYMP), July 2018, pp. 24-29.

[10] M. S. Diab, A. A. Elserougi, A. M. Massoud, A. S. Abdel-Khalik, and S. Ahmed, "A pulsewidth modulation technique for high-voltage gain operation of three-phase z-source inverters," IEEE Journal of Emerging and Selected Topics in Power Electronics, vol. 4, no. 2, pp. 521-533, June 2016.

[11] E. R. Collins, J. R. Shirley, and J. C. Fox, "An experimental investigation of third harmonic current distortion in single-phase induction motors," in 2008 13th International Conference on Harmonics and Quality of Power, Sept 2008, pp. 1-7. 